\title{
Evaluation of Quality of Service in 4th Generation (4G) Long Term Evolution (LTE) Cellular Data Networks
}

\author{
Fahad Alomary ", Ivica Kostanic \\ Department of Electrical and Computer Engineering, Florida Institute of Technology, Melbourne, 32901, Florida, Unites States \\ *Corresponding Author: falomary@my.fit.edu
}

Copyright $@ 2013$ Horizon Research Publishing All rights reserved.

\begin{abstract}
The area of study proposed in this paper is the evaluation of the Quality of Service (QoS) provided by a Long Term Evolution (LTE) cellular data network. It is aimed to address the gap between the technical capabilities and the QoS experienced by the user. The analysis is based on the live data that are collected on commercial cellular network and compared against broadband wireless LAN. A methodology for QoS assessment based on a relatively small set of Key Performance Indicators (KPIs) is devised. The measured data are used to verify the proposed methodology.
\end{abstract}

Keywords Drive-test data collection, HTTP, LTE, QoS measurements, Wi-Fi.

\section{Introduction}

Data services are changing our life in a profound way. Cellular providers make Internet connectivity available anywhere and anytime. This allows for instantaneous access to social networks, employment Intranet, academic environments, shopping, Internet browsing, entertainment etc. From the user perspective, it is important that regardless of the access platform, there is a guarantee of the QoS with respect to the experience. Cellular companies strive to improve service and provide better experience to their users. Research and development in various areas of cellular technologies has allowed for growth, and advanced development of cellular broadband services. . Cellular telecommunication services became a valid alternative of traditional broadband landline connection service. Currently deployed advanced cellular standard is $4 \mathrm{G}$ Long Term Evolution (LTE) which allows cellular companies to provide even more advanced services in an efficient manner. With the development of LTE, the speed of the data transmission has increased with respect to the mobile and fixed broadband. The LTE offers support for more services such as voice, data, video and multimedia. It is based on OFDM/OFDMA (Orthogonal Frequency Division Multiplexing / Orthogonal Frequency Division Multiple Access) which is well suited to achieve high peak data rates in high spectrum bandwidth and multipath fading channel. LTE has the capability to use packet data at higher bit rates. The usage of advanced access, and transmission techniques for both the transmission bandwidth and QoS of cellular networks have been improved. Table 1 shows LTE network parameters.

The networks of 4G LTE hold a promise of performance that is comparable or even better than the broadband services provided by landline Wi-Fi access. However, even though the technical limits are high, due to the complexities associated with the cellular data networks, it is a frequent case that a user never sees the top performance of the underlying technology.

Table 1. LTE Network Parameters

$\begin{array}{cc}\text { Key Parameters } & \text { 4G LTE } \\ \text { Access Technology } & \text { OFDM/OFDMA } \\ \text { Duplex Schemes } & \text { FDD and TDD } \\ \text { Latency } & \sim 10 \mathrm{~ms} \mathrm{RTT} \\ \text { Bandwidth } & 100 \mathrm{MHz} \\ \text { Mobile Top Speed } & 200 \mathrm{~km} / \mathrm{h} \\ \text { Frequency Band } & 2 \text { to } 8 \mathrm{GHz} \\ \text { Data Rate } & \text { Up to } 100 \mathrm{Mbps} \text { in downlink } \\ \end{array}$

Key Performance Indicators (KPIs) help define the performance metrics of a network. They allow cellular operators to maintain their networks so that the users remain satisfied. KPIs are calculated from measurements of various network parameters. KPIs represent an equations based upon simple counters that are used to give a more meaningful measurement of performance. For example, a simple counter, such as the numbers of times the users connect to the network, has a little meaning. However, the ratio of successful connections and the number of connection attempts represents the success rate - which is an important indicator of the performance quality. It is a much better indication of the performance of the network. QoS is a measure of the network quality as it relates to the user 
experience. Some examples of the QoS parameters would be achieved with the success rate, average throughput, and throughput jitter. One may attempt to characterize QoS of a network is by using these three significant parameters. The area of study proposed in this paper is the evaluation of QoS in a cellular data network. At present, this is a problem that exists despite the fact there are large volumes of measured performance data collected on various nodes of cellular networks. There is still no unified approach that is endorsed by the community on how these data are to be analyzed, processed and presented.

\section{QoS Methodology}

The proposed method for QoS evaluation in a cellular network consists of three steps. In the first step, a set of controlled measurements is preformed. The second step the measurements are used for KPI calculations. In the last step the KPIs are compared with the KPI obtained from a broadband network. To illustrate the methodology, the measurements are collected on three different networks: Wi-Fi available in a common home environment (802.11g), Wi-Fi provided in a common office environment $(802.11 \mathrm{n})$, and commercial LTE cellular network. The data are checked for integrity, filtered, and processed. In all three networks, the following data services are evaluated: HTTP Web browsing, FTP download, FTP upload, video streaming, and connectivity delay (test ping).

The method that is explored provides KPIs of the QoS parameters within the network. The essential issue is that KPIs, such as the power levels, do not correlate directly with the user experience. The proposed method allows network operators to see how the data they gather from testing the network relates to the subjective users experience. Providers will use the data interpretation to adjust certain network parameters to better meet the users expected QoS.

\subsection{Data Collection}

\subsubsection{Equipment setup}

All necessary QoS measurements are collected using specialized software operating on commercial grade drive test equipment. The equpment setup, shown in Fig. 1, consists of:

- Laptop computer: HP Pavilion dm4-1060us running Windows 7 Home Premium and collection software.

- LTE Cell Phone: SAMSUNG Galaxy S III that allows 4G LTE service.

- Generic GPS (Global Position System) device: provides the time and location mapped measurements.

- Collection software: JSDU E6474A Drive Test -
Wireless Network Optimization Software. Used to setup tests and collection of data.

- Analysis software: Gladiator G-Station software is a tool for efficient process-management, consolidation, integration, analysis, and correlation of data collected.

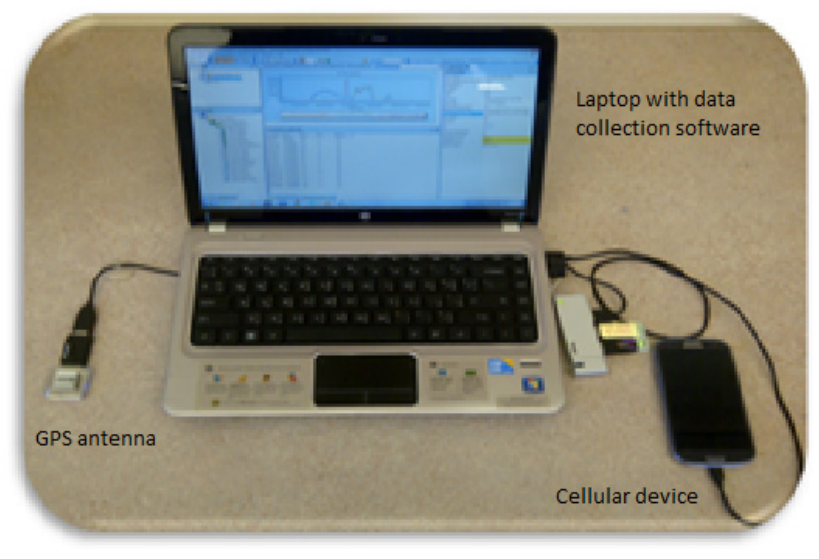

Figure 1. QoS test equipment setup

\subsubsection{The Data Collection}

The collection software is set to measure the following data services: HTTP Web browsing, FTP download, FTP upload, video streaming, and ping. The test and relevant measurements are shown in Table 2. All tests are run in cycles, as illustrated in Fig. 2. Service-based tests are explained as following:

- HTTP (HyperText Transfer Protocol) tests provide measurements as shown in Table 2. The measurements are collected during the period of time from when a HTTP request is sent through the network until the last byte of HTTP page is received.

- FTP (File Transfer Protocol) tests provide measurements as listed in Table 2. The measurements are obtained for transferring large and small files.

- Video streaming tests provide measurements as shows in Table 2. The measurements are collected during the period of time from when a request is sent to the network to the time when the video is received.

- PING tests provide measurements as presented in Table 2. PING task perform network connectivity and performance using small payloads.2.2. Data processing

In this step, data collected are processed in order to find major statistical measures, such as minimum, maximum, and average values for all collected KPIs. 


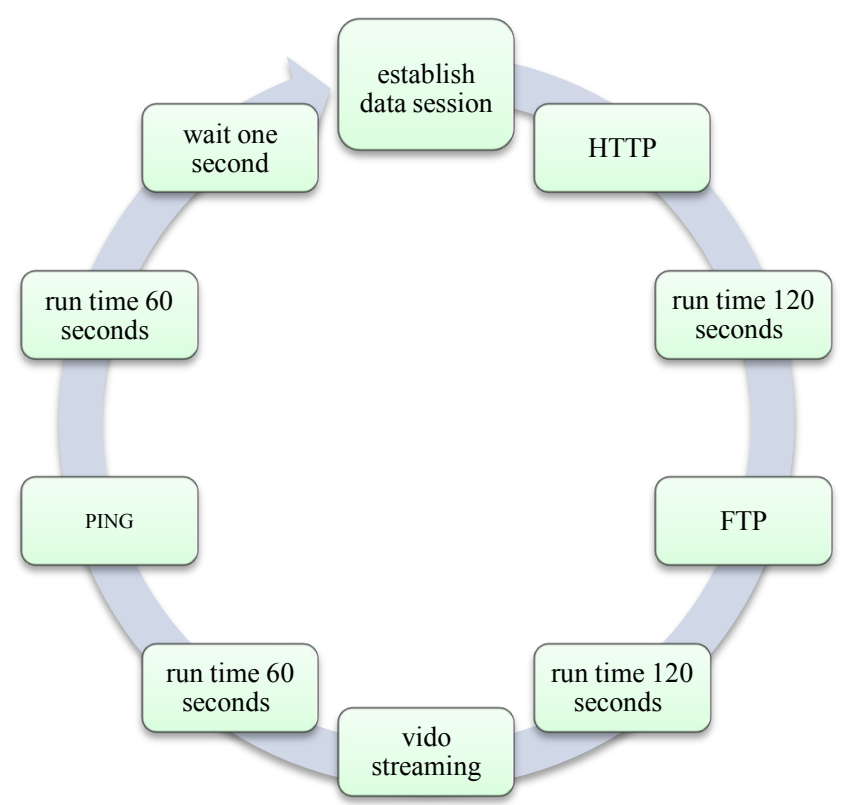

Figure 2. The diagram shows the test cycle used for the test

Table 2. QoS measurements for different LTE services

\begin{tabular}{|c|c|c|c|c|}
\hline NO. & HTTP & FTP & Video Streaming & PING \\
\hline 1 & Success \& Failure & Success \& Failure & Count Time & Count Time \\
\hline 2 & Total Size & Total Time & Success \& Failure & Success \& Failure \\
\hline 3 & Total Time & Total Throughput & Success rate (\%) & Success rate (\%) \\
\hline 4 & Download Throughput & $\begin{array}{c}\text { The Domain Name System } \\
\text { (DNS) Time }\end{array}$ & Buffer Time & Ping Task Duration \\
\hline 5 & $\begin{array}{c}\text { Download Application } \\
\text { Throughput }\end{array}$ & Connect Time & Set up Time & RTT (Round Trip Time) \\
\hline 6 & & Response Time & Streaming time & TTL (Time To Live) \\
\hline 7 & & Authentication Time & Packets received & Jitter \\
\hline 8 & & Put Time & & \\
\hline 9
\end{tabular}

As illustrated in Fig. 2, QoS test cycle starts with HTTP test. There are four different websites used for the test. The number of successful connections and failures for each website are counted. The test measures the total count of HTTP access, success, and success rate. The success rate of HTTP for all three broadband networks is shown in Fig. 3. If the connection does not go through in 120 seconds it is considered as failed. The total size measured in $(\mathrm{kB})$, it indicates the minimum, the maximum, and the mean download application throughput. The application throughput of HTTP for all three broadband networks is shown in Fig. 4. After the application throughput, the test demonstrates the download throughput for each website, measured in (kbps). The download throughput indicates the minimum, the maximum, and the mean download throughput. The results of HTTP for all three broadband networks are shown in Tables 4, 8, and 12.

After the HTTP, the test cycle moves to a series of the FTP download and FTP upload measurements. Two file sizes are used: a large and a small file. A large file has size of 3.38MB.
The number of times to run is 1 . Time out is 120 seconds. A small file has size of $141 \mathrm{kB}$. The number of times to run is 1 . Time out is 60 seconds. The test measures the FTP success and the failure of the downloading and uploading small and large files. It demonstrates the total time count of the FTP downloading and uploading small and large files, success, and success rate. The success rate of FTP for all three broadband networks is shown in Fig. 3. Besides the success rate, the test measures FTP application throughput of downloading small and large files. The application throughput of FTP for all three networks under test is shown in Fig. 4. After downloading the files, the test measures the FTP application throughput of uploading small and large files. The results of FTP download and upload for the networks are shown in Tables 5, 9, and 13.

After FTP download and upload, the test cycle moves to video streaming. The test reports count of the video streaming session, success, and success rate. Streaming video measurements show the minimum, and the maximum throughput and the mean throughput jitter. The file size used 
in the test is $239 \mathrm{kB}$, and it contains a video that is 1 minute and 34 Seconds long. The number of times to run the test in a cycle is 1 . Time out is 60 seconds. The video streaming results for the three networks are shown in Tables 6,10 , and 14.

The final test in a cycle performs ping measurements. The test measures ping count, ping success, ping failure, and ping success rate. The success rate for all is shown in Fig. 3. The number of times to run is 1 . Time out is 60 seconds. The data size is 32 Bytes. The results of ping measurements for the networks are shown in Tables 7,11 , and 15 .

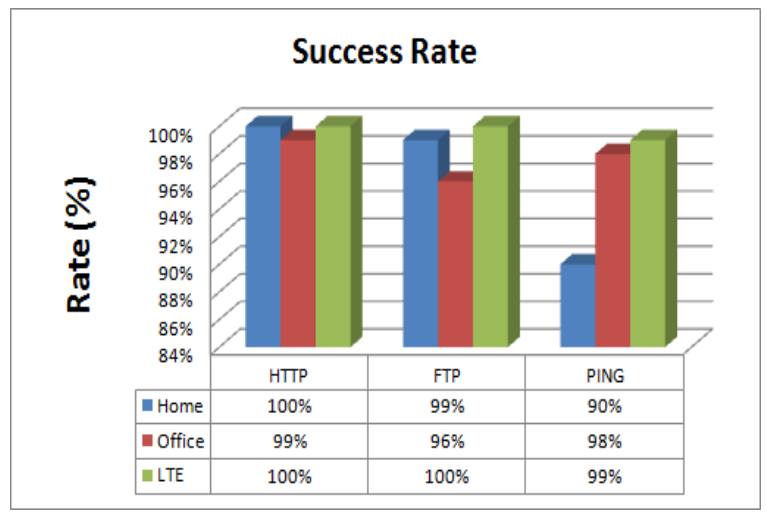

Figure 3. The success rate

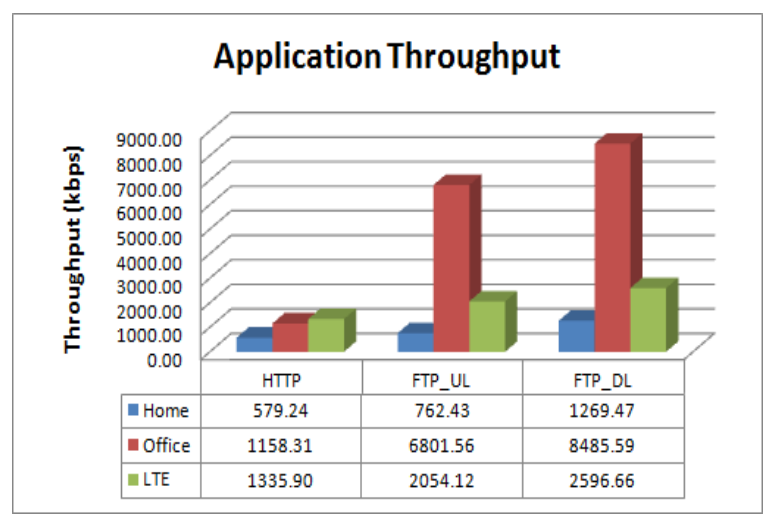

Figure 4. The application throughput

\subsection{Data Analysis}

The objective of the data collection is the comparison of the user experience across different wireless networks. With the help of G-station software the measured data are imported and a set of various KPIs is calculated. Through the KPIs and the other measurements gathered from the tests, one may make a case by case assessment of a connection which provided good quality of service. In this study, the networks are compared using the following three basic QoS parameters; success rate, average throughput, and throughput jitter. Each one of the QoS parameters is an important component of the wireless cellular network performance [2]. The three QoS KPI parameters are explained as follows:

1) Success rate - is defined as the percentage of service attempts with respect to all service attempts.

2) Average throughput - is the average of all call throughput measurements obtained from the call start time to the call end time. It is measured in kilobits per second (kbps).

3) Jitter - is the standard deviation of the throughput over the period of a call. It is measured in kilobits per second/second (kbps).

Based on these three QoS parameters, a scoring matrix like the one shown in Table 3 may be constructed. Each of the QoS parameters has a ranking from one to five. Each is based on different thresholds which may be used for QoS evaluation of the network. The thresholds are reflection of current practice.

\section{Presentation of Results}

Data Quality Index (DQI) is used to evaluate the Quality of Service (QoS) of cellular data networks [3]. The scoring system is from one to five, where one indicates the lowest quality, and five indicates the highest quality as demonstrated in Table 3. For example, the network may receive the highest score on the success rate parameters if $99 \%$ of the tests are setup successfully. The blocking probability of the network should be no more than $1 \%$. The QoS parameter score is presented as si DQI is a weighted average of QoS parameters scores. The ais are weights associated with individual scores. DQI equation is shown below:

$$
\mathrm{DQI}=\sum_{i=1}^{n} \text { ai } x \text { si }
$$

A network with highest DQI score is perceived to be the one with the best user experience. The score is technology and network independent, which makes it suitable for QoS evaluations. Each KPI measurement is scored based on the range defined in Table 3.

Table 3. QoS parameter scores

\begin{tabular}{|c|c|c|c|c|c|}
\hline Score & 1 & 2 & 3 & 4 & 5 \\
\hline $\begin{array}{c}\text { Success rate } \\
(\%)\end{array}$ & $<80$ & $81-85$ & $86-96$ & $97-98$ & $>99$ \\
\hline $\begin{array}{c}\text { Throughput } \\
(\mathrm{kbps})\end{array}$ & $<250$ & $251-500$ & $501-750$ & $751-1000$ & $\begin{array}{c}> \\
1001\end{array}$ \\
\hline $\begin{array}{c}\text { Jitter } \\
(\mathrm{kbps} / \mathrm{s})\end{array}$ & $>180$ & $170-179$ & $160-169$ & $150-159$ & $<140$ \\
\hline
\end{tabular}

\subsection{Summary of results from home environment}

The collecting of data began on the $23^{\text {rd }}$ of June 2011 and continued through June $24^{\text {th }} 2011$. The test was scheduled to begin at 6:00PM and ended at 12:00PM. The home testing site is located in the suburbs of Melbourne, Florida. Melbourne is a coastal city located on the east coast of Central Florida.

The data were collected by using a laptop that was equipped with (JDSU) E6474A Wireless Network 
Optimization Software, and utilized a $802.11 \mathrm{~g}$ wireless connection with a connectivity speed up to $54 \mathrm{Mbps}$. After the collection of the KPI measurements, the post processing was conducted using the Gladiator G-Station software. The analysis produced Tables 4 through 7 :

Table 4. HTTP measurements

\begin{tabular}{|l|c|c|c|c|}
\hline \multirow{2}{*}{ HTTP tests } & \multicolumn{1}{l}{} \\
\hline Web site & Web_1 & Web_2 & Web_3 & Web_4 \\
\hline Count & 619 & 619 & 619 & 619 \\
\hline Success & 619 & 619 & 619 & 619 \\
\hline Success rate & $100 \%$ & $100 \%$ & $100 \%$ & $100 \%$ \\
\hline Application Throughput mean (kbps) & 1345.6 & 4983.12 & 2517.75 & 467.17 \\
\hline Application Throughput min (kbps) & 841 & 3525 & 1452 & 142.18 \\
\hline Application Throughput max (kbps) & 6970 & 11236 & 9583 & 562.46 \\
\hline Throughput mean(kbps) & 735.05 & 594.71 & 527.52 & 459.68 \\
\hline Throughput min(kbps) & 167.86 & 235.32 & 118.46 & 132.87 \\
\hline Throughput max (kbps) & 1123.68 & 864.52 & 779.6 & 576.12 \\
\hline
\end{tabular}

Table 5. FTP download and upload measurements

\begin{tabular}{|c|c|c|c|c|}
\hline FTP test & & & & \\
\hline Type of test & FTP_DL_SMALL & FTP_DL_LARGE & FTP_UL_SMALL & FTP_UL_LARGE \\
\hline Count & 310 & 310 & 310 & 310 \\
\hline Success & 309 & 307 & 309 & 299 \\
\hline Success rate & $100 \%$ & $99 \%$ & $100 \%$ & $96 \%$ \\
\hline $\begin{array}{l}\text { Total application tput DL - mean } \\
\text { (kbps) }\end{array}$ & 714.77 & 1824.16 & & \\
\hline $\begin{array}{l}\text { Total application tput DL - min } \\
\text { (kbps) }\end{array}$ & 208.77 & 530.18 & & \\
\hline $\begin{array}{l}\text { Total application tput DL - max } \\
\text { (kbps) }\end{array}$ & 1255.16 & 2423.31 & & \\
\hline $\begin{array}{l}\text { Total application tput UL - mean } \\
\text { (kbps) }\end{array}$ & & & 811.59 & 713.26 \\
\hline $\begin{array}{l}\text { Total application tput UL - min } \\
\text { (kbps) }\end{array}$ & & & 482.96 & 233.8 \\
\hline $\begin{array}{l}\text { Total application tput UL - max } \\
\text { (kbps) }\end{array}$ & & & 1090.28 & 1394.45 \\
\hline
\end{tabular}

Table 6. Video streaming measurements

\begin{tabular}{|l|c|}
\hline Streaming video test & \multicolumn{2}{|c|}{239} \\
\hline Count & 234 \\
\hline Success & $98 \%$ \\
\hline Success rate & 174.06 \\
\hline Jitter - $\operatorname{mean}(\mathrm{ms})$ & 163 \\
\hline Jitter - $\min (\mathrm{ms})$ & 188 \\
\hline Jitter - $\max (\mathrm{ms})$ & \\
\hline
\end{tabular}

Table 7. PING measurements

\begin{tabular}{|l|c|}
\hline Ping test & \multicolumn{2}{|c|}{ All Four Websites } \\
\hline Website & 7762 \\
\hline Count & 6971 \\
\hline Success & $90 \%$ \\
\hline Success rate & \\
\hline
\end{tabular}

\subsection{Summary of Results from Office Environment}

The collecting of data was scheduled on the $20^{\text {th }}$ of June 2011. The test was scheduled to begin at $11 \mathrm{AM}$ and ended at 6:30PM. The office testing site is located in Melbourne, Florida close to the Melbourne International Airport. The wireless access is $802.11 \mathrm{n}$. The analysis produced Tables 8 through 11:

Table 8. HTTP measurements

\begin{tabular}{|l|c|c|c|c|}
\hline \multirow{2}{*}{ HTTP tests } & \multicolumn{5}{l|}{} \\
\hline Web site & Web_1 & Web_2 & Web_3 & Web_4 \\
\hline Count & 1198 & 1198 & 1198 & 1198 \\
\hline Success & 1195 & 1193 & 1193 & 1194 \\
\hline Success rate & $99 \%$ & $99 \%$ & $99 \%$ & $99 \%$ \\
\hline Application Throughput mean (kbps) & 771.48 & 3038.89 & 1053.29 & 686.44 \\
\hline Application Throughput min (kbps) & 370 & 2143 & 601 & 87.56 \\
\hline Application Throughput max (kbps) & 6279 & 15803 & 8683 & 1142.54 \\
\hline Throughput mean(kbps) & 1812.41 & 952.26 & 1184.14 & 684.43 \\
\hline Throughput min (kbps) & 174.19 & 145.58 & 131.89 & 78.21 \\
\hline Throughput max (kbps) & 3045.76 & 1280.42 & 1845.63 & 1136.05 \\
\hline
\end{tabular}

Table 9. FTP download and upload measurements

\begin{tabular}{|c|c|c|c|c|}
\hline FTP test & & & & \\
\hline Type of test & FTP_DL_SMALL & FTP_DL_LARGE & FTP_UL_SMALL & FTP_UL_LARGE \\
\hline Count & 603 & 603 & 603 & 603 \\
\hline Success & 578 & 578 & 579 & 578 \\
\hline Success rate & $96 \%$ & $96 \%$ & $96 \%$ & $96 \%$ \\
\hline $\begin{array}{l}\text { Total application tput DL - mean } \\
\text { (kbps) }\end{array}$ & 7813.82 & 9157.36 & & \\
\hline $\begin{array}{l}\begin{array}{l}\text { Total application tput DL - min } \\
\text { (kbps) }\end{array} \\
\end{array}$ & 503.97 & 372.75 & & \\
\hline $\begin{array}{l}\text { Total application tput DL - max } \\
\text { (kbps) }\end{array}$ & 22617.97 & 21433.79 & & \\
\hline $\begin{array}{l}\text { Total application tput UL - mean } \\
\text { (kbps) }\end{array}$ & & & 6368.93 & 7234.18 \\
\hline $\begin{array}{l}\begin{array}{l}\text { Total application tput UL - min } \\
\text { (kbps) }\end{array} \\
\text { (n) }\end{array}$ & & & 276.1 & 849.46 \\
\hline $\begin{array}{l}\text { Total application tput UL - max } \\
\text { (kbps) }\end{array}$ & & & 22617.97 & 20213.08 \\
\hline
\end{tabular}

Table 10. Video streaming measurements

\begin{tabular}{|l|c|}
\hline Streaming video test & \\
\hline Count & 595 \\
\hline Success & 583 \\
\hline Success rate & $98 \%$ \\
\hline Jitter - mean $(\mathrm{ms})$ & 168.34 \\
\hline Jitter $-\min (\mathrm{ms})$ & 160 \\
\hline Jitter $-\max (\mathrm{ms})$ & 172 \\
\hline
\end{tabular}

Table 11. PING measurements

\begin{tabular}{|l|c|}
\hline Ping test & \multicolumn{2}{|c|}{ All Four Websites } \\
\hline Website & 9602 \\
\hline Count & 9443 \\
\hline Success & $98 \%$ \\
\hline Success rate & \\
\hline
\end{tabular}

\subsection{Summary of Results from Drive Test}

The collection of the data was scheduled on the $21^{\text {st }}$ of May 2013. The drive test was began at 11:00AM and ended at 5:00PM. The drive test was performed in Melbourne Florida, and Palm Bay Florida Fig. 5. The two towns are adjacent to each other, and allow for a smooth flow of traffic. The tests were conducted in suburban, urban, industrial, and commercial areas within the two towns. The analysis produced Tables 12 through 15: 


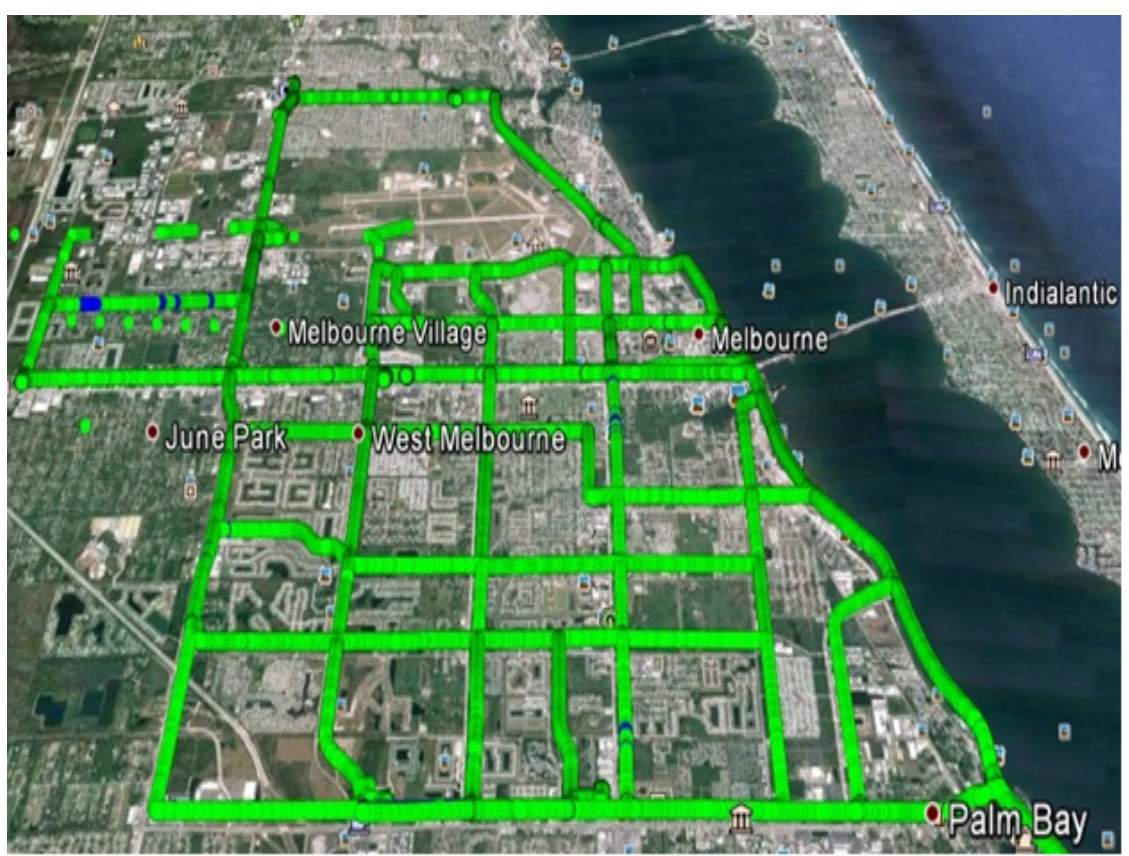

Rx Power $(\mathrm{dBm})$

- $<-102(0-0.00 \%)$

-102 to $-94(0-0.00 \%)$

-94 to $-90(12-0.13 \%)$

-90 to $-84(219-2.30 \%)$

-84 to $-74(3374-35.44 \%)$

$>-74(5914-62.13 \%)$

Figure 5. Drive test range - Melbourne and Palm Bay, FL

Table 12. HTTP measurements

\begin{tabular}{|l|c|c|c|c|}
\hline HTTP tests & \multicolumn{3}{|l|}{} \\
\hline Web site & Web_1 & Web_2 & Web_3 & Web_4 \\
\hline Count & 174 & 174 & 174 & 174 \\
\hline Success & 174 & 174 & 174 & 174 \\
\hline Success rate & $100 \%$ & $100 \%$ & $100 \%$ & $100 \%$ \\
\hline Task duration - mean(ms) & 1500.41 & 3030.4 & 17420.56 & 15241.82 \\
\hline Task duration min(ms) & 1123 & 1451 & 15116 & 3198 \\
\hline Task duration max (ms) & 4447 & 71223 & 21677 & 71329 \\
\hline Throughput mean(kbps) & 2031.49 & 1934.92 & 568.66 & 808.56 \\
\hline Throughput min(kbps) & 600.08 & 128.25 & 453.39 & 53.63 \\
\hline Throughput max (kbps) & 2450.89 & 2813.1 & 648.15 & 1294.88 \\
\hline
\end{tabular}

Table 13. FTP download and upload measurements

\begin{tabular}{|c|c|c|c|c|}
\hline \multicolumn{5}{|l|}{ FTP test } \\
\hline Type of test & FTP_DL_SMALL & FTP_DL_LARGE & FTP_UL_SMALL & FTP_UL_LARGE \\
\hline Count & 87 & 87 & 87 & 87 \\
\hline Success & 87 & 87 & 87 & 87 \\
\hline Success rate & $100 \%$ & $100 \%$ & $100 \%$ & $100 \%$ \\
\hline $\begin{array}{l}\text { Total application tput DL - mean } \\
\text { (kbps) }\end{array}$ & 2282.52 & 2910.81 & & \\
\hline $\begin{array}{l}\text { Total application tput DL - min } \\
\text { (kbps) }\end{array}$ & 979.13 & 1487.47 & & \\
\hline $\begin{array}{l}\text { Total application tput DL - } \max \\
(\mathrm{kbps})\end{array}$ & 3015.73 & 3814.1 & & \\
\hline $\begin{array}{l}\text { Total application tput UL - mean } \\
\text { (kbps) }\end{array}$ & & & 1673.34 & 2434.91 \\
\hline $\begin{array}{l}\text { Total application tput UL - min } \\
(\mathrm{kbps})\end{array}$ & & & 442.1 & 820.02 \\
\hline $\begin{array}{l}\text { Total application tput UL - } \max \\
\text { (kbps) }\end{array}$ & & & 2336.57 & 4488.89 \\
\hline
\end{tabular}


Table 14. Video streaming measurements

\begin{tabular}{|l|c|}
\hline Streaming video test & \multicolumn{1}{|c|}{87} \\
\hline Count & 87 \\
\hline Success & $100 \%$ \\
\hline Success rate & 173.26 \\
\hline Jitter - mean $(\mathrm{ms})$ & 173 \\
\hline Jitter $-\min (\mathrm{ms})$ & 174 \\
\hline Jitter $-\max (\mathrm{ms})$ & \\
\hline
\end{tabular}

Table 15. PING measurements

\begin{tabular}{|l|c|}
\hline Ping test & \multicolumn{2}{|c}{ All Four Websites } \\
\hline Website & 1479 \\
\hline Count & 1466 \\
\hline Success & $99 \%$ \\
\hline Success rate & $99 \%$ \\
\hline
\end{tabular}

Table 16. The comparison between home, office, and LTE drive test

\begin{tabular}{|c|c|c|c|c|c|c|c|c|c|}
\hline & & Home & Office & HSPA & LTE & Score home & Score office & \begin{tabular}{|l|} 
Score LTE \\
\end{tabular} & Weight \\
\hline \multirow[b]{2}{*}{ HTTP } & throughput & 579.24 & 1158.31 & 447.3 & 1335.9 & 3 & 5 & 5 & 0.25 \\
\hline & success rate $[\%]$ & 100 & 99.6 & 100 & 100 & 5 & 5 & 5 & 0.04 \\
\hline \multirow[b]{2}{*}{ FTP_DL_small } & throughput & 714.77 & 7813.82 & 536.79 & 2282.52 & 3 & 5 & 5 & 0.04 \\
\hline & success rate $[\%]$ & 99.99 & 96 & 100 & 100 & 5 & 3 & 5 & 0.04 \\
\hline \multirow[b]{2}{*}{ FTP_DL_large } & throughput & 1824.16 & 9157.36 & 1174.66 & 2910.81 & 5 & 5 & 5 & 0.04 \\
\hline & success rate $[\%]$ & 99 & 96 & 90 & 100 & 5 & 3 & 5 & 0.04 \\
\hline \multirow[b]{2}{*}{ FTP_UL_small } & throughput & 811.59 & 6368.93 & 488.59 & 1673.34 & 4 & 5 & 5 & 0.04 \\
\hline & success rate $[\%]$ & 99.99 & 96 & 100 & 100 & 5 & 3 & 5 & 0.04 \\
\hline \multirow[b]{2}{*}{ FTP_UL_large } & throughput & 713.26 & 7234.18 & 853.89 & 2434.91 & 3 & 5 & 5 & 0.04 \\
\hline & success rate $[\%]$ & 96 & 96 & 74 & 100 & 3 & 3 & 5 & 0.04 \\
\hline \multirow[b]{2}{*}{ V.S } & jitter & 174.06 & 168.34 & 172.37 & 173.26 & 2 & 3 & 2 & 0.35 \\
\hline & success rate $[\%]$ & 98 & 98 & 84 & 100 & 4 & 4 & 5 & 0.04 \\
\hline & & & & & DQI & 3.13 & 3.94 & 4.3 & \\
\hline
\end{tabular}

\subsection{The Comparison between home, office, and LTE drive test}

The summary of results from the three broadband networks is shown in Table 16. The three QoS parameters success rate, average throughput, and jitter are compared. The weighted average of QoS parameters has a range between zero and one. The weight value depends of the importance of a given service to the end user. Therefore, weights vary depending on the type of service used. Customers using web services are not likely to notice the effects of high jitter as they would when watching a video streaming. When weights vary, the weight of video streaming is likely to remain high within all applications. The users that cannot establish a connection to the network are discouraged regardless of what kind of service they wish to use.
Based on the obtained DQI values for all three networks, commercial LTE cellular network (drive test) provides the best user experience and it has the highest DQI score. However, DQI value calculated for LTE networks approaches Wi-Fi home experience. This result makes LTE networks very competitive with traditional broadband services.

\section{Conclusions}

The paper demonstrates how to measure network performance by using the Key Performance Indicators (KPIs). KPI is an evaluation criterion that measures the QoS of a data network. KPIs are used as a basic unit of measurement for monitoring the QoS of the network. The research presented in this paper is addressing two points. 
First: based upon the collected data, a set of meaningful measurements are proposed. These measurements are technology agnostic. Their main purpose is to capture the user's experience within the network's QoS. Second: based upon the collected measurements, a set of KPI's is calculated. The KPI's are used to determine a meaningful set of metrics that objectively quantify the user experience. Therefore, it allows an approach to compare different networks regardless of the underlying technology. Future work will allow comparison of performance between different network environments with other wireless data networks.

\section{Acknowledgments}

The authors would like to express a sincere an appreciation to Nenad Mijatovic for support of the research presented in this paper. Also, many thanks to the reviewers whose constructive critique greatly improved the quality of the paper.

\section{REFERENCES}

[1] M. Junaid Arshad, Amjad Farooq, Abad Shah, "Evolution and Development Towards 4th Generation (4G) Mobile Communication Systems", Journal of American Science, 2010
[2] Ira Weissberger, Ivica Kostanic, Carlos E. Otero, "Evaluation of HTTP QoS in a UMTS Network", 2010

[3] Ivica Kostanic, Nenad Mijatovic, Stephen D. Vest, "Measurement Based QoS Comparison of Cellular Communication Networks", 2009

[4] Mohamed Kadhem Karray, "Analytical Evaluation of QoS in the Downlink of OFDMA Wireless Cellular Networks Serving Streaming and Elastic Traffic", 2010

[5] Bilal Haider, M. Zafrullah, M. K. Islam, "Radio Frequency Optimization \& QoS Evaluation in Operational GSM Network", October 20-22, 2009, San Francisco, USA

[6] Erik Dahlman, Stefan Parkvall, Johan Sköld, Per Beming, 3G EVOLUTION HSPA AND LTE FOR MOBILE BROADBAND, 2nd Edition, Elsevier Ltd, 2008

[7] Pierre Lescuyer, Thierry Lucidarme, EVOLVED PACKET SYSTEM (EPS), John Wiley \& Sons, England, 2008

[8] Mohamed Kadhem Karray, "Evaluation of the Blocking Probability and the Throughput in the Uplink of Wireless Cellular Networks", 2010

[9] Georges Nogueira, Bruno Baynat, Ahmed Ziram, "An Efficient Analytical Model for QoS Engineering in Mobile Cellular Networks", 2008

[10] Robert Lloyed-Evans, QoS Integrated 3G Networks, Artech house, Inc., 2002 Steffen Sroka, Holger Karl, "Performance Evaluation of a QoS-Aware Handover Mechanism", Proceedings of the Eighth IEEE International Symposium on Computers and Communication (ISCC'03), 2003

[11] http://www.gsma.com/ 